\title{
Factors deterring and prompting the decision to attempt suicide on the railway networks: findings from 353 online surveys and 34 semi-structured interviews - ADDENDUM
}

Lisa Marzano, Jay-Marie Mackenzie, Ian Kruger, Jo Borrill and Bob Fields

\section{Keywords}

Suicide; metro; underground; rail; suicide methods; addendum.

\section{Copyright and usage}

(c) The Royal College of Psychiatrists 2019 https://doi.org/10.1192/bjp.2018.303, Published online by Cambridge University Press, 07 February 2019

The acknowledgments section is missing from the final published article by Marzano, et al. The complete acknowledgments section is provided below. The authors apologise for the omission.

Lisa Marzano; Jay-Marie Mackenzie; Ian Kruger; Jo Borrill; Bob Fields

\section{Acknowledgements}

We are greatly indebted to the hundreds of people who generously shared their time, stories, and experiences with us.

This programme of research was commissioned by Samaritans and funded by Network Rail on behalf of the rail industry. We are grateful to the Project Stakeholder Group for their support throughout the research, particularly lan Stevens, Rachel Watters and Caroline Kingston (Network Rail), Kim Tuley (British Transport Police), Michael Woods (RSSB), Gary Cooper
(ATOC (Association of Train Operating Companies) and National Task Force) and Susie Beevor (ATOC), Stephanie Aston, Ola Rzepczynska and Lorna Fraser (Samaritans). The late Mark Smith, MBE, Head of Suicide Prevention and Mental Health at British Transport Police, played a key role in supporting this research, and several other initiatives to prevent suicide on the railways. His dedicated and intelligent approach to suicide prevention has helped save many lives, and inspired countless others.

Thanks are also due to Professor Keith Hawton, Fiona Malpass, lan Noonan, and Professor Damien Ridge, who provided invaluable advice and support at several stages of the project, and to Professor Andrea Cipriani for all his help and feedback on the manuscript.

Additional thanks are due to the National Suicide Prevention Alliance (NSPA), Rethink Mental Illness, and CALM (Campaign Against Living Miserably) for their assistance with participant recruitment, to Stephanie Aston and many others at Samaritans for enabling us to conduct research interviews at local branches, and Andy Bardill, Kate Herd and Kirsty Tither of Redloop (Middlesex University) for help with the study website and recruitment materials.

\section{Reference}

Marzano L, Mackenzie J-M, Kruger I, Borrill J, Fields B. Factors deterring and prompting the decision to attempt suicide on the railway networks: findings from 353 online surveys and 34 semi-structured interviews. Br J Psychiatry 2019; 1-6.

\section{The vulnerability paradox in global mental health and its applicability to suicide - CORRIGENDUM}

Michel L. A. Dückers, Lennart Reifels, Derek P. De Beurs and Chris R. Brewin

Keywords

Suicide; transcultural psychiatry; epidemiology; corrigendum.

\section{Copyright and usage}

(c) The Royal College of Psychiatrists 2019 https://doi.org/10.1192/bjp.2019.41, Published online by Cambridge University Press, 20 March 2019

This article erroneously states that Lennart Reifels is affiliated with Monash University Accident Research Centre, Monash University, Australia. In fact, he is a Senior Research Fellow at the Centre for Mental Health, Melbourne School of Population and Global Health, The University of Melbourne, Carlton, Australia.
Michel L.A. Dückers; Lennart Reifels; Derek P. De Beurs; Chris R. Brewin

\section{Reference}

Dückers MLA, Reifels L, De Beurs DP, Brewin CR. The vulnerability paradox in global mental health and its applicability to suicide. Br J Psychiatry 2019; 1-6. doi: 10.1192/ bjp.2019.41. 